\title{
Evaluation on Effect of Implementation of Clinical Nursing Teachers' Professional Growth Management Model
}

\author{
Ma Xiumei $^{1}$, Yang Liqun ${ }^{2,}$, Ma Yuexian ${ }^{1}$, Liu Wei ${ }^{1}$, Wei Hongjuan ${ }^{2}$ \\ ${ }^{1}$ Affiliated hospital of Qiqihar Medical University, Qiqihar, Heilongjiang, 161006, China \\ ${ }^{2}$ Qiqihar Medical University
}

Keywords: clinical nursing teachers; professional growth management model; nursing students; teaching ability; satisfaction

\begin{abstract}
To evaluate the effect of professional growth management model applied to clinical nursing teacher management. Clinical nursing teachers from the same hospital were selected as the study objects. The teachers in observation group received professional growth management model and those in control group received conventional management model. After the intervention of different management modes, overall teaching ability of clinical nursing teachers, students' professional theory test, operation test scores, and clinical nurse teaching satisfaction from nursing students were observed in the two groups.
\end{abstract}

\section{Introduction}

The teaching method of nursing is different from conventional teaching and has certain characteristics. Nursing students often understand the basic process of nursing during clinical practice, practice nursing methods, combine theoretical knowledge and practical ability, and improve the overall quality of nursing students. The role of clinical nursing teachers in this process is very important, not only to lead nursing students to familiarize themselves with routine nursing methods and to scientifically guide them, but also to shoulder the important task of cultivating the basic clinical practice abilities and professional emotions of nursing students. In short, the overall quality of nursing students is closely related to the quality of teaching of clinical nursing teachers [1-3]. How to improve the teaching quality of clinical nursing teachers and their overall professional quality and promote their professional growth is the focus of the majority of nursing educators and managers. Relevant studies have shown that [4], there are many problems in the current nursing teaching, such as weak teachers, teaching management system is not perfect and clinical nursing teaching models and methods are relatively old. This study uses a historical comparison study to evaluate the impact of professional growth management models on the career growth of clinical nursing teachers. The following is reported:

\section{Materials and Methods}

\subsection{General Information}

Sixty-five clinical nursing teachers working in a hospital from June 2014 to June 2016 were selected as the study subjects, and the subjects were from 33 first-line clinical training departments such as internal medicine, surgery, obstetrics and gynecology, and pediatrics. The subjects met the following inclusion criteria: 1) clinical nurses who had worked for more than three years; 2) the last academic qualifications were undergraduate and above; 3) were able to quickly accept and understand new things; 4) had good professional qualities. Exclusion criteria: 1) Those who do not meet the above criteria for inclusion; 2) Those who cannot actively cooperate. There were 4 males and 61 females, aged 23-46 years old, with an average of (35.12 \pm 5.77$)$ years old. Both of them are undergraduates; there are 42 nurses in charge and 23 nurses. 


\subsection{Methods}

The control group (from June 2014 to June 2015 to undertake clinical nursing practice teaching) to implement the conventional management model: to undertake clinical internships before teaching The nursing department to provide uniform training for clinical nursing teachers, teaching during the internship, experienced teaching. The teacher shared the experience of nursing and teaching. The teachers in the daily tutors explored each other. After the tutoring, they were evaluated and evaluated. The nurses of clinical nursing who had a good effect on nursing education were rewarded and praised.

The observation team (from June 2015 to June 2016 to undertake clinical nursing practice teaching) implements the professional growth management model: It mainly manages through the following aspects.

1) Establish an incentive mechanism: clinical nurses play an important role in both medical treatment and teaching, and give clinical nurses certain policy incentives, such as timely payment of lecture fees, evaluation of awards, priority learning, etc. The enthusiasm of clinical teaching, the more positive teaching attitude, the more active and active explanation of nursing students, the improvement of the knowledge of nursing students and the mastery of clinical practice, and the promotion of harmony between nursing students and clinical nurses. It also helps improve professional nurses' professional ethics, theoretical teaching ability, and management skills for nursing students.

2) Improve the management system: The quality of clinical nurses' teaching and the knowledge collection of nursing students are positively correlated with the clinical practice ability. Periodically assess the clinical nurses to ensure that the clinical nurses have a high level of business, good communication skills, and good skills. Nursing skills and better teaching ability are essential for clinical teaching. Through regular assessment of clinical nursing teachers' professional knowledge, operational ability and teaching ability.

3) To increase the degree of attention of clinical nursing teachers to teaching: To correct and guide the teachers who are not good in their teaching attitudes, to standardize their nursing teaching behaviors, to make them aware of the importance of nursing teaching, to constantly update the teaching concept, and to improve the teaching quality. Establish a good professional image in teaching and actively conduct professional emotional education.

4) Regularly organize clinical nursing teacher training classes and training courses: clinical nursing teaching not only requires higher professional knowledge level, skilled nursing operation ability, but also needs scientific and reasonable clinical teaching ability, and organizes different trainings through regular clinical teacher training. Levels and different forms of training courses provide multi-faceted training for clinical nursing teachers in theoretical teaching ability, guiding clinical operation ability, professional knowledge level, and interpersonal communication and communication skills to form a training system to improve the overall teaching of clinical nurses.

5) Exchange of experience and interaction between full-time teachers and clinical nursing teachers: With the strong advantages of the affiliated hospitals of medical schools, regular exchange meetings and seminars are held in a "twin-pair" way, and full-time teachers and clinical nurses share experience sharing. The full-time teachers and clinical nurses actively communicate and interact with each other, take their essence, constantly update the teaching methods and concepts, improve the teaching procedures and methods of clinical nursing teachers, and promote clinical nursing teaching more scientific and standardized.

\subsection{Observation Indicators}

1) The overall professional competence of clinical nursing teachers: According to the relevant standards in the "Guidance on Clinical Practice Teaching of Nursing" [5], the judgment is made. A questionnaire survey was conducted on two groups of clinical nursing teachers to observe and record their professional knowledge level and operation ability, clinical teaching ability, and professional quality. The assessment scores were statistically analyzed. The three types of questionnaires are rated 100 points. The higher the score, the higher the overall professional 
competence of clinical nursing teachers.

2) Nursing student test scores: In order to comprehensively evaluate the impact of professional growth management model on the career growth of clinical nursing teachers, this study needs to evaluate the performance of nursing students and their satisfaction with the teachers. Therefore, we chose June 2014- June 2015, 90 intern trainees internship at our hospital served as a control group. Ninety-six nursing students practiced in our hospital from June 2015 to June 2016 served as observation teams. The general information of the two groups of students was not Statistical significance $(\mathrm{P}>0.05)$. The examinations for nursing students include the results of professional theory examinations and nursing technical operation examinations, with a perfect score of 100 points. The higher the score, the better the clinical knowledge of nursing students.

3) Nursing students' satisfaction with clinical nursing teachers: Nursing students evaluate the teaching teachers in terms of their teaching attitudes, teaching abilities, and teaching methods. The satisfaction questionnaire has a total of 100 points. The higher the score is, the higher the satisfaction is. Among them, 80-100 are very satisfied, 60-79 are more satisfactory, 40-59 are less satisfied, and 39 or less are not satisfied. Total satisfaction rate $=[$ (very satisfied + more satisfactory) / total number of cases] $\times 100 \%$.

\subsection{Statistical Analysis}

SPSS 17.0 was used to count and analyze the overall professional competence of nurses, the results of nursing students' examinations, and the degree of nursing students' teaching satisfaction. The measurement data were expressed as mean \pm standard deviation $( \pm s)$, and t-tests were used.The rate (\%) represents the count data, using the test; $\mathrm{P}<0.05$ was considered statistically significant.

\section{Results}

\subsection{Comparison of Overall Professional Capabilities}

The overall professional ability score of the observation group was significantly higher than that of the control group $(\mathrm{P}<0.05)$. See Table 1.

Table 1 Comparison of overall professional competence of clinical nurses in the two groups

\begin{tabular}{|c|c|c|c|c|}
\hline Group & Number & $\begin{array}{c}\text { Professional knowledge } \\
\text { level and operation } \\
\text { ability }\end{array}$ & $\begin{array}{c}\text { Clinical teaching } \\
\text { ability }\end{array}$ & $\begin{array}{c}\text { Professional } \\
\text { quality }\end{array}$ \\
\hline $\begin{array}{c}\text { Observation } \\
\text { group }\end{array}$ & 65 & $96.23 \pm 6.16$ & $91.06 \pm 5.78$ & $90.17 \pm 6.88$ \\
$\begin{array}{c}\text { Control group } \\
\text { t }\end{array}$ & 65 & $87.12 \pm 5.88$ & $86.89 \pm 6.67$ & $78.26 \pm 7.02$ \\
P & & -8.6247 & -3.8092 & -9.8679 \\
& 0.000 & 0.000 & 0.000
\end{tabular}

\subsection{Nursing students compared scores}

The theoretical test scores and operation test scores of nursing students in the observation group were significantly higher than those in the control group $(\mathrm{P}<0.05)$. See Table 2 .

Table 2 Comparison of the scores of the two groups of nursing students

\begin{tabular}{|c|c|c|c|}
\hline Group & Number & Theory test results & Operation test results \\
\hline Observation group & 96 & $95.12 \pm 4.23$ & $90.25 \pm 5.66$ \\
Control group & 90 & $89.11 \pm 5.26$ & $85.33 \pm 6.85$ \\
$\mathrm{t}$ & & -8.6123 & -5.3533 \\
$\mathrm{P}$ & & 0.000 & 0.000 \\
\hline
\end{tabular}




\subsection{Nursing student's teaching satisfaction to clinical nurses}

The satisfaction rate of the nurses in the observation group with nurses was significantly higher than that in the control group. There was a statistically significant difference between the two groups $(\mathrm{P}<0.05)$. See Table 3.

Table 3 Comparison of Teaching Satisfaction Rates between Nurse Students and Clinical Nurses in Two Groups

\begin{tabular}{|c|c|c|c|c|c|c|}
\hline Group number & Number & $\begin{array}{c}\text { Very } \\
\text { satisfied }\end{array}$ & $\begin{array}{c}\text { Relatively } \\
\text { satisfied }\end{array}$ & $\begin{array}{c}\text { Not quite } \\
\text { satisfied }\end{array}$ & $\begin{array}{c}\text { Not } \\
\text { satisfied }\end{array}$ & $\begin{array}{c}\text { Total } \\
\text { satisfaction } \\
\text { rate }\end{array}$ \\
\hline $\begin{array}{c}\text { Observation } \\
\text { group }\end{array}$ & 96 & 25 & 65 & 4 & 2 & $93.75 \%$ \\
$\begin{array}{c}\text { Control group } \\
x^{1}\end{array}$ & 90 & 12 & 55 & 13 & 10 & $74.44 \%$ \\
$P$ & & & \multicolumn{1}{c|}{$\begin{array}{c}15.3213 \\
0.0016\end{array}$} \\
\hline
\end{tabular}

\section{Discussion}

The professional level, teaching ability and professional quality of clinical nursing teachers have great influence on the clinical learning and practice of nursing students. How to explain and guide clinical nurses in nursing students' practice stage to learn effective clinical knowledge, fully understand the clinical nursing process, and implement effective and reasonable nursing programs, so as to improve the combination of knowledge and practice of nurse students in the internship process. Degree, so that nursing students fully understand their own deficiencies and to supplement, is the focus of clinical nursing teachers and intern nurses [6-9]. Foreign research shows that [10-11], through the establishment of a system of teaching teachers with certificates, can effectively promote the standardization of clinical teaching, improve nurses' sense of responsibility, improve the effectiveness of clinical teaching, but also through the clinical nursing teachers to carry out standardized management and training to improve clinical nurses professional knowledge level and clinical teaching level, and enhance teaching effectiveness. However, at present there is no scientific and effective management model implemented in the country [12].

The professional growth management model manages clinical nursing teachers from multiple aspects, effectively and systematically improves clinical nurses' professional ethics, professional knowledge, nursing operation skills, interpersonal and communication skills, and clinical guidance for nursing students. Improving the teaching attitude and philosophy of clinical nurses and improving the enthusiasm of nursing students [13-15]. Among the five major aspects, the establishment of an incentive mechanism is mainly through the provision of preferential policies for clinical nursing teachers to send out learning, advanced studies, timely lecture fees, and evaluation of awards, so as to mobilize the teaching enthusiasm of clinical nursing teachers and facilitate the teaching of nursing teachers. Improve your teaching attitude, improve professional ethics, teaching students in the clinical teaching more vivid, so that nursing students have a deeper understanding of clinical nursing practice; improve the clinical nursing teacher management system, through regular assessment, preferential appointment Improving the overall level of clinical nursing teachers, rewarding those with exceptional excellence, standardizing clinical nursing teaching methods and procedures, and improving the quality of teaching; strengthening clinical nurses' emphasis on teaching is mainly through popularizing knowledge among clinical teachers. Teachers recognize their own teaching responsibilities and the significance and importance of clinical teaching, so as to increase the importance of teaching quality and teaching methods, help clinical nurses to effectively and reasonably carry out teaching; holding clinical nursing teacher training classes and training classes are mainly through regular hosting. The training course at the same level and in forms provides training for clinical nurses. It provides professional training for the weak aspects of teaching methods of different clinical nurses to improve the overall professional competence of 
clinical nurses. At the same time, it employs experienced experts to teach standardized teaching methods and improve Clinical nurses' teaching ability. At the same time pay attention to the exchange of experience with full-time teachers and communication, regular exchange meetings, sharing of teaching experience through full-time teachers through clinical nursing teachers, improve their own teaching philosophy and teaching methods.

The results of this study show that after intervention of different management models, the overall professional competence of the clinical nursing teachers in the observation group was significantly higher than that of the control group. The results of nursing students' grades and the nursing students' satisfaction with clinical nursing teachers were all improved. Reflects the professional growth management model applied to the management of clinical nursing teachers, can effectively improve the clinical nurse professional knowledge level and operation ability, clinical teaching ability and professional quality, and change the teaching philosophy and teaching attitude of clinical nursing teachers. The clinical teaching of nurse students adopts a more vivid and effective method of teaching, which promotes the harmony between nursing students and the tutors and improves the effect of clinical teaching.

\section{Conclusion}

In summary, the professional growth management model applied to the management of clinical nursing teachers can effectively improve their overall professional ability and teaching level, and is conducive to nursing students' grasp of clinical knowledge and operating practices, and is worthy of clinical promotion and application.

\section{Acknowledgement}

This article is the result of the project Heilongjiang Education Department Humanities and Social Science Project (12542335)

\section{References}

[1] Papathanasiou I V, Tsaras K, Sarafis P. Views and perceptions of nursing students on their clinical learning environment: Teaching and learning[J]. Nurse education today, 2014, 34(1): 57-60.

[2] Wang Xue.Construction and implementation of standardized management model for clinical nursing teachers[J]. Shanghai Nursing,2013,13(03):27-29.

[3] Zhang Xueping, Shen Ying, Zhuang Haifeng, et al. Application of multi-mode nursing teaching rounds in clinical teaching of specialist nurses[J]. Chinese Nursing Management, 2014, 14(03): 312-314.

[4] Yang Rong, Li Li, Li Xingmei. Discussion on Problems and Teaching Modes of Clinical Nursing Teaching[J]. Chinese and Foreign Medical Research, 2014, 12(27):137-138.

[5] Fang Xiuxin, Wang Qinghua. Nursing clinical practice teaching guidelines [M]. Beijing: People's Medical Publishing House, 2009:363-364.

[6] Li Hongzhi, LIU Qianqian. Analysis of factors affecting the quality of clinical nursing teaching and countermeasures[J]. Chinese Medical Innovation, 2013, 10(01): 141-142.

[7 Wu Saifen, Lu Yalin, Deng Jieying, et al. Application of nursing scientific research achievements in promoting continuous improvement of surgical nursing teaching quality [J]. Qilu Nursing Journal, 2013, 19(08): 18-20.

[8] Liu Yuling. Problems in clinical nursing teaching management and discussion of teaching mode[J]. Heilongjiang Medical Journal, 2014, 27(04): 975-976.

[9] Yang Jinxia,Chen Cuiping. Research progress in the competence of clinical nursing teachers[J]. Journal of Nursing Management,2014,14(10):723-725. 
[10] Kristofferzon ML, Mårtensson G, Mamhidir AG, et al. Nursing students' perceptions of clinical supervision: The contributions of preceptors, head preceptors and clinical lecturers[J]. Nurse education today, 2013, 33(10): 1252- 1257.

[11] Wiklund Gustin L, Wagner L. The butterfly effect of caring-clinical nursing teachers' understanding of self-compassion as a source to compassionate care[J]. Scandinavian Journal of Caring Sciences, 2013, 27(1): 175-183.

[12] Yang Shilai, Wang Xiaoxia. Research progress in clinical nursing teaching[J]. Journal of Nursing, 2015, 22(24): 34-36.

[13] Huang Liqun, Sun Lihong, Huang Xiaozhen. Clinical nursing teaching quality management and monitoring strategy[J]. Qilu Nursing Journal, 2013, 19(09): 118-119.

[14] Lei Ruihong, Fei Hong, Xia Yinfang. Application of teacher-student dynamic mutual evaluation method in clinical nursing teaching quality control[J]. Journal of Nursing Science, 2014, 29(15):14-16.

[15] Tang Yuanhong, Zhao Shumin, Lv Min. Research on the strategy of "institution cooperation" training management mode to improve teaching ability of clinical nursing teachers[J]. Chinese General Practice Medicine, 2015, 13(09): 1531-1533. 